\title{
Influence of Grandparental Child Care on Childhood Obesity: A Systematic Review and Meta-Analysis
}

\author{
Ruopeng An, PhD, Xiaoling Xiang, $\mathrm{PhD}^{2}, \mathrm{Na} \mathrm{Xu}, \mathrm{PhD}^{3}$ and Jing Shen, $\mathrm{PhD}^{4}$
}

\section{Abstract}

Objective: This study systematically reviewed the scientific literature on the relationship between grandparental child care and childhood obesity.

Methods: Keyword/reference search was performed in CINAHL, PsycINFO, PubMed, and Web of Science. Meta-analysis was conducted to estimate the pooled effect of grandparental child care on children's weight outcomes.

Results: A total of 23 studies were identified, including 9 longitudinal, 9 cross-sectional, 2 case-control, and 3 qualitative studies. Eight studies were conducted in China, five in Japan, three in the United Kingdom, two in the United States, and one in five other countries each. Twelve studies focused on grandparents' roles as a main caregiver in the family, and seven on grandparents' coresidence. Data from 14 studies were used in meta-analysis, 10 focusing on childhood overweight/obesity and the other 4 on children's BMI z-scores. Meta-analysis found that grandparental child care was associated with a 30\% $(95 \%$ confidence interval $=21-40)$ increase in childhood overweight/obesity risk. Grandparental child care was not associated with children's BMI z-scores after correcting for publication bias. Meta-regressions revealed no difference in the estimated effect of grandparental child care on children's weight outcomes by country or grandparents' specific roles (main caregiver in the family vs. co-residence).

Conclusions: Preliminary evidence links grandparental child care to elevated risk of childhood overweight/obesity, but not BMI z-scores. Future research should focus on a specific child age group within a country, adopt systematic and field-validated measures on grandparental child care, and elucidate the pathways linking grandparental child care to children's weight outcomes.

Keywords: grandparent; meta-analysis; obesity; review

\section{Introduction}

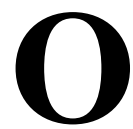
besity is a leading cause of morbidity and premature mortality worldwide. ${ }^{1-4}$ Childhood obesity is linked to various immediate and long-term adverse health outcomes such as sleep apnea, hypertension, heart disease, stroke, type 2 diabetes, osteoarthritis, and certain types of cancer, and it leads to social and psychological problems such as stigmatization and poor self-esteem. ${ }^{5,6} \mathrm{In}$ 2010, 43 million children worldwide (35 million in developing countries) were estimated to be overweight or obese. ${ }^{7}$ The prevalence of childhood overweight/obesity is projected to reach $9 \%$ or 60 million children in $2020{ }^{8}$

As obesity is a result of energy imbalance, healthful diet and physical activity are the core of childhood obesity prevention effort. ${ }^{9}$ Family-based interventions are a key strategy in promoting these healthy lifestyle behaviors, given family's highly influential role in supporting and managing children's energy balance through parenting practices and the family environment. ${ }^{10,11}$ Family-based interventions have conventionally included parents as an integral target. There is a proliferation of original studies and reviews focused on the roles of parents in childhood obesity and family-based interventions involving parents. ${ }^{12}$ Less attention is placed on the influence of other caregivers in the family, such as grandparents.

A secondary analysis of nationally representative survey data found that children with normal-weight parents and obese grandparents had twice the risk of being overweight themselves than children with normal-weight parents and normal-weight grandparents, ${ }^{13}$ suggesting that grandparents had an influence on child weight status distinct from

\footnotetext{
'Brown School, Washington University, St. Louis, MO.

${ }^{2}$ School of Social Work, University of Michigan, Ann Arbor, MI.

${ }^{3}$ Shanghai University, Shanghai, China.

${ }^{4}$ Overseas Chinese College, Capital University of Economics and Business, Beijing, China.
} 
parental influence. Demographic shifts (e.g., increased life expectancy) and changes in family structures (e.g., the rise of single-parent households and working moms) have seen an increase in the number of grandparents who provide extensive child care to their grandchildren. ${ }^{14}$ Today's grandparents are more than occasional visitors and gift bearers, but play an essential role in raising the next generation.

In the United States, grandparents care for as many children as formal child care programs do: almost one in four children under age 5 were routinely cared for by a grandparent, while parents worked or attended school. ${ }^{15}$ In many developing countries such as China, grandparental child care is even more prevalent and plays more significant roles in child care. Grandparents routinely perform activities ranging from getting young children ready for school in the morning, grocery shopping with them, planning and cooking family meals, and taking them to the playground to providing full-time child care for preschoolers and acting as the custodial parent to children whose parents are unwilling or unable to provide care. ${ }^{16,17}$

Such activities transform the grandparent from the more traditional older-generation-in-the-family roles into roles typically assumed by a child's parents, and in some cases, grandparent becomes the primary caregiver. ${ }^{18}$ As grandparents increasingly assume the role of parents in children's lives, they exert more influence over children's diet, physical activity, and other behaviors (e.g., sleep) that affect energy balance. ${ }^{19-21}$

The rising awareness among researchers regarding the important roles of grandparents has resulted in an increase in the number of studies that examined the relationship between grandparental child care and childhood obesity. ${ }^{22-25}$ Findings from these studies remain inconclusive: some studies reported a higher risk of childhood obesity among children cared for by grandparents than those under parental care only ${ }^{22,26,27}$ and some reported null findings, ${ }^{28}$ whereas some suggested the positive impact of grandparental child care on reducing childhood obesity through contributing to a more balanced $\operatorname{diet}^{29}$ and increased physical activity among children. ${ }^{19}$

To identify patterns in research findings and gaps in knowledge, we conducted a systematic review and metaanalysis to appraise and synthesize quantitative studies on the relationship between grandparental child care and childhood obesity. To our knowledge, there has not yet been a systematic review and meta-analysis focusing on the role of grandparental child care on children's body weight. Such reviews are both important and timely, given the increased number of grandparents routinely providing child care and studies investigating the link between grandparental child care and childhood obesity. Findings from such reviews will identify targets for intervention, help refine existing family-based interventions, and inform future research and practice to combat childhood obesity.

\section{Methods}

\section{Study Selection Criteria}

Studies that met all of the following criteria were included in the review: (1) study design: observational studies (e.g., longitudinal studies, case-control studies, or crosssectional studies) or qualitative studies; (2) study subjects: children 17 years of ages and younger; (3) exposure: grandparental child care; (4) outcomes: body weight status (e.g., BMI percentile or z-score, or childhood overweight or obesity); (5) article type: peer-reviewed publications; (6) time window of search: from the inception of an electronic bibliographic database to July 15, 2019; (7) geographical location: worldwide; and (8) language: articles written in English.

Studies that met any of the following criteria were excluded from the review: (1) studies that incorporated no outcome pertaining to children's body weight status; (2) exposures without grandparental child care; (3) articles not written in English; or (4) letters, editorials, study/review protocols, or review articles.

\section{Search Strategy}

A keyword search was performed in four electronic bibliographic databases: CINAHL, PsycINFO, PubMed, and Web of Science. The search algorithm is provided in Table 1. Titles and abstracts of the articles identified through the keyword search were screened against the study selection criteria. Potentially relevant articles were retrieved for evaluation of the full text. Two co-authors of this review independently conducted title and abstract screening and identified potentially relevant articles. Inter-rater agreement was assessed using the Cohen's kappa $(\kappa=0.82)$. Discrepancies were resolved through discussion under the participation of a third co-author.

A reference list search (i.e., backward reference search) and a cited reference search (i.e., forward reference search) were conducted based on the full-text articles meeting the study selection criteria that were identified from the keyword search. Articles identified from the backward and forward reference search were further screened and evaluated using the same study selection criteria. Reference search was repeated on all newly identified articles until no additional relevant article was found.

\section{Data Extraction and Preparation}

A standardized data extraction form was used to collect the following methodological and outcome variables from each included study: first author, publication year, country, year of study, study design, sample age group, sample size, age range, proportion of female participants, statistical model, nonresponse rate, urbanicity, family role of grandparents, type of body weight status measure, detailed measure of body weight status, estimated effects of grandparental child care on body weight status, and secondary outcomes (e.g., physical activity and/or diet). 


\section{Table I. Search Algorithm}

\begin{tabular}{|c|c|}
\hline Group & Keywords \\
\hline Grandparent-related & 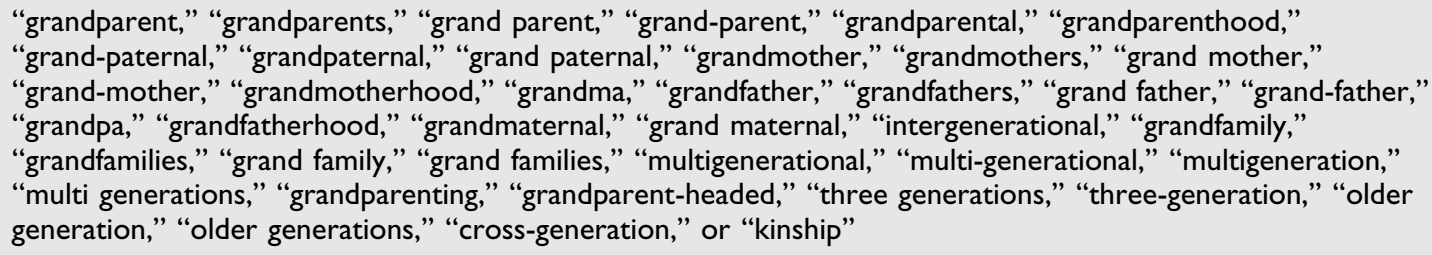 \\
\hline Obesity-related & $\begin{array}{l}\text { "obesity," "obese," "adiposity," “overweight," "body mass index," "BMI," "body weight," "waist circumference," } \\
\text { "waist to hip," "waist-to-hip," or "body fat" }\end{array}$ \\
\hline Grandchild-related & 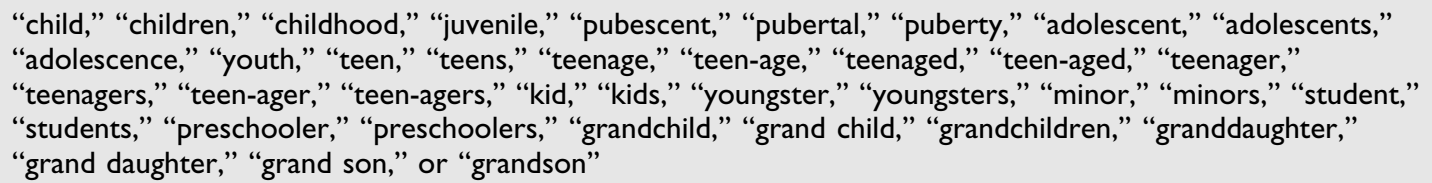 \\
\hline
\end{tabular}

\section{Meta-Analysis}

Meta-analysis was performed to estimate the pooled effect of grandparental child care on children's body weight status. Separate models were estimated for the two outcomes: childhood overweight/obesity and the BMI z-score. For the outcome of childhood overweight/obesity, studies were selected for meta-analysis if they reported the estimated risk ratios and/or odds ratios for childhood overweight/obesity. For the outcome of BMI z-scores, studies were selected for meta-analysis if they reported the estimated coefficients for BMI z-scores. Study heterogeneity was assessed using the $I^{2}$ index. The level of heterogeneity represented by the $I^{2}$ index was interpreted as small $\left(I^{2} \leq 25 \%\right)$, moderate $\left(25 \%<I^{2} \leq\right.$ $50 \%)$, large $\left(50 \%<I^{2} \leq 75 \%\right)$, or very large $\left(I^{2}>75 \%\right)$.

A fixed-effect model was performed when the heterogeneity level was small or moderate, whereas a random-effect model was performed when the heterogeneity level was large or very large. Random-effect meta-regressions were conducted to assess the potential moderating effects of country and type of care (caregiving vs. co-residence) on the relationship between grandparental child care and children's body weight status. Publication bias was evaluated using funnel plot and Begg's and Egger's tests. ${ }^{30}$ A nonparametric trim-and-fill method would be used to correct for publication bias if either Begg's or Egger's test was statistically significant (i.e., $p<0.05$ ). All statistical analyses were performed using Stata 15.1 SE version (StataCorp, College Station, TX).

\section{Study Quality Assessment}

We used the National Institutes of Health's Quality Assessment Tool for Observational Cohort and CrossSectional Studies to assess the quality of each included study. ${ }^{31}$ This assessment tool rates each study based on 14 criteria. For each criterion, a score of 1 was assigned if "yes" was the response, whereas a score of 0 was assigned otherwise. A study-specific global score ranging from 0 to 14 was calculated by summing up scores across all criteria. The study quality assessment helped measure the strength of scientific evidence, but was not used to determine the inclusion of studies.

\section{Results}

\section{Identification of Studies}

Figure 1 shows the study selection flow chart. We identified a total of 2109 articles through the keyword and reference search. After removing duplications, 1609 unique articles underwent title and abstract screening, in which 1584 articles were excluded. The full texts of the remaining 25 articles were reviewed against the study selection criteria. Of these, two articles were excluded. The primary reasons for exclusion are lack of outcome pertaining to childhood obesity and adult sample instead of children and/ or adolescents. The remaining 23 studies that examined the relationship between grandparental child care and children's body weight status were included in the review. ${ }^{16,17,19-29,32-}$

${ }^{41}$ Fourteen studies were included in the meta-analyses, as shown in Table 4 (4 studies on BMI z-scores ${ }^{32,33,37,38}$ and 10 studies on childhood overweight/obesity risk $^{19,22-26,28,34-36}$ ).

\section{Basic Characteristics of the Included Studies}

Table 2 summarizes the basic characteristics of the 23 included studies. Eight studies were conducted in China, five in Japan, three in the United Kingdom, two in the United States, and one each in Greek, European countries, Central African Republic, Sweden, and Turkey. All included studies were published in or after 2010 - one in 2014, two each in 2010 and 2011, three each in 2018 and 2019, and four each in 2013, 2015, and 2017. Two studies adopted a case-control study design, three adopted a qualitative study design, nine adopted a longitudinal study design, and the remaining nine adopted a cross-sectional study design.

Sample sizes were generally large, but varied substantially across studies. Two studies had a sample size between 10 and 99, nine had a sample size between 100 and 999, seven had a sample size between 1000 and 9999, and 


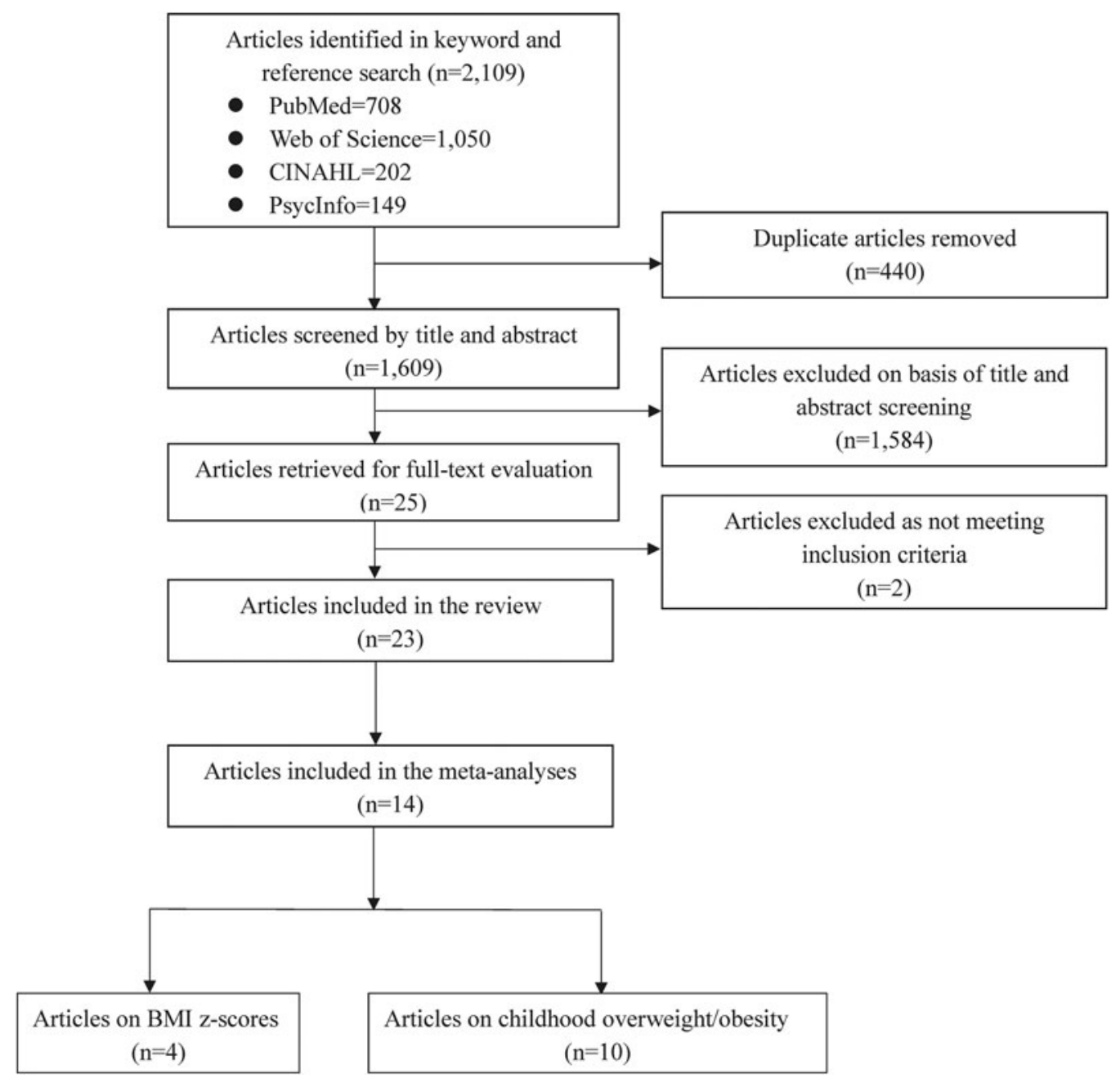

Figure 1. Study selection flowchart.

the remaining five had a sample size above 10,000 . The mean and median sample sizes were 5636 and 1867, respectively, with a standard deviation of 9500 and a range from 14 to 43,046 .

We categorized the study samples by age groups - infants $0-2$ years of age, children 3-11 years of age, and adolescents 12-17 years of age. Two studies recruited infants, the majority $(n=19)$ of studies recruited children, one recruited both infants and children, and the remaining one recruited both children and adolescents. All included studies recruited both girls and boys, largely equally distributed in the samples. A variety of statistical models were applied across studies, including Spearman's correlation coefficient, linear regression, logistic regression, conditional logistic regression, Poisson regression, fixed-effect model, mixed-effect model, ANOVA, and ANCOVA. The majority of studies $(n=16)$ adjusted for some individual sociodemographic and/or family characteristics in the statistical analysis.

\section{Key Findings of the Included Studies}

Table 3 summarizes measures and estimated effect of grandparental child care on children's body weight status.
Twelve studies focused on grandparents' roles as a main caregiver in the family, seven studies focused on grandparents' co-residence, two studies focused on grandparents' presence, one study focused on both grandparents' roles as a main caregiver in the family and grandparents' co-residence, and the remaining one focused on emotional and social support from grandparents.

Body weight status measures included BMI $(n=1)$, body weight $(n=1)$, weight for height $(n=1)$, BMI z-score $(n=5)$, and overweight and/or obesity status $(n=15)$. BMI-related measures were based on objectively measured height and weight $(n=21)$. Beside children's weight outcomes, 11 studies also reported the estimated effects of grandparental child care on children's diet and/or physical activity behaviors.

The estimated effects of grandparental child care on children's weight outcomes differed across the studies included in the review. In some studies, grandparents being a main caregiver in the family was found to be positively associated with childhood overweight and/or obesity, ${ }^{19,22-28}$ children's BMI z-scores, ${ }^{32}$ and children's mean BMI over time. ${ }^{33}$ Absence of grandparental child care was found to be potentially protective for migrant children's obesity risk. ${ }^{20} \mathrm{In}$ 


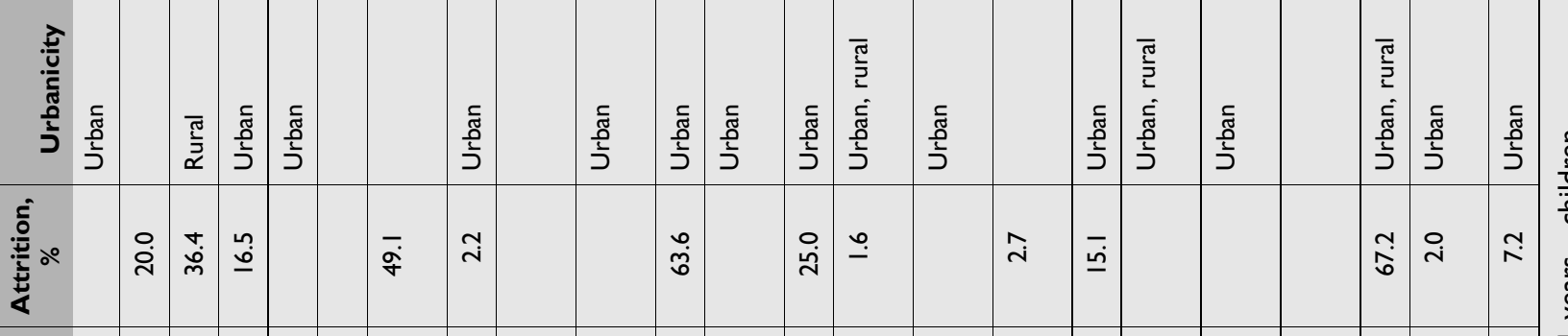

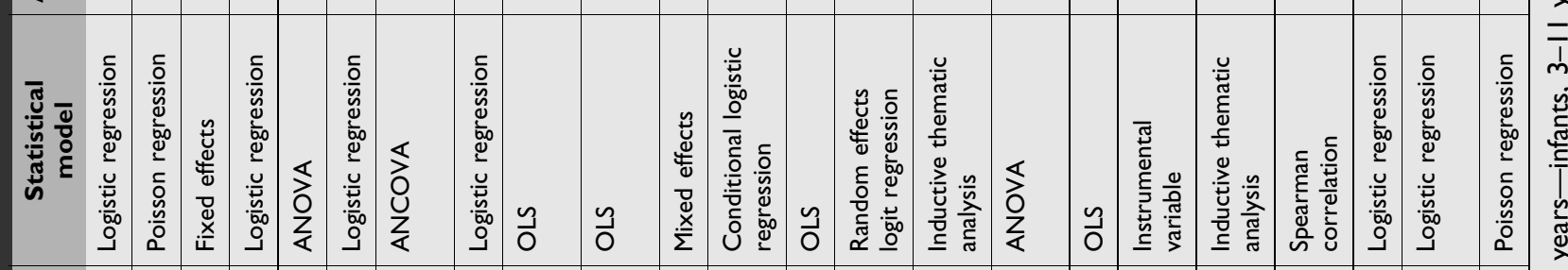

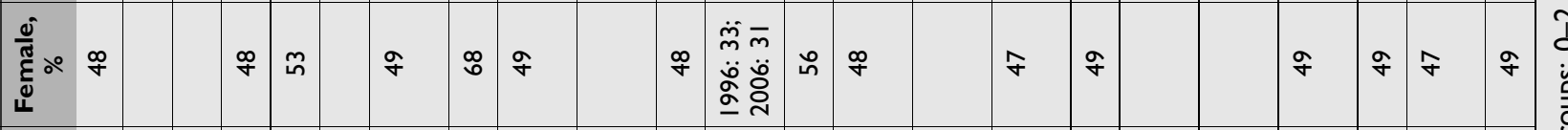

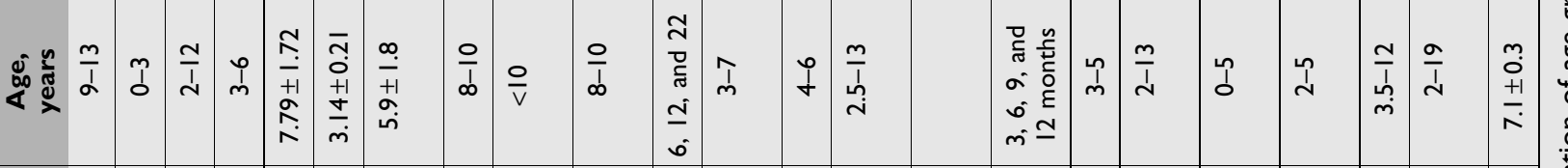

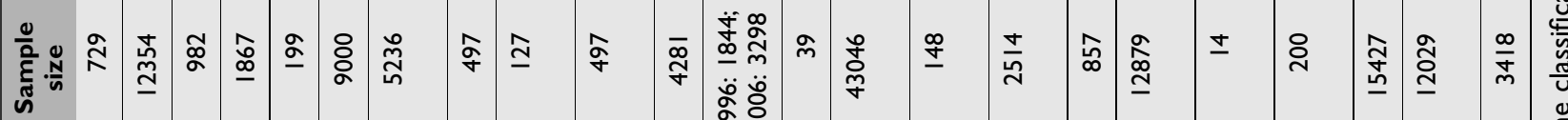

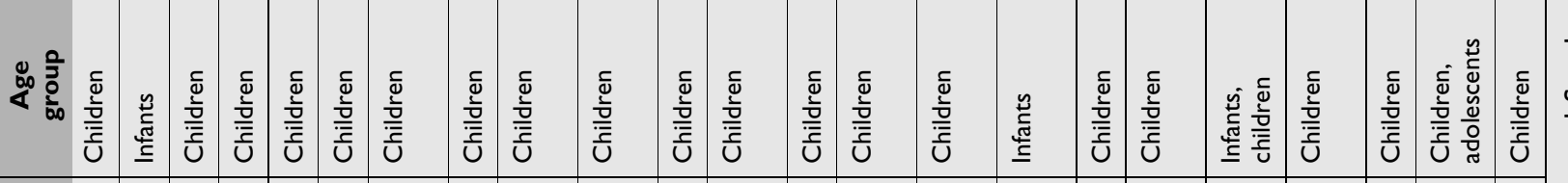

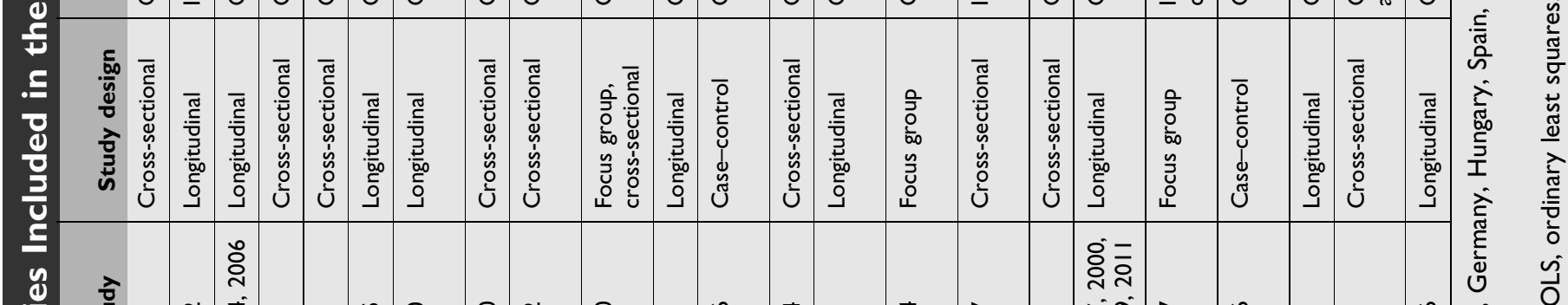

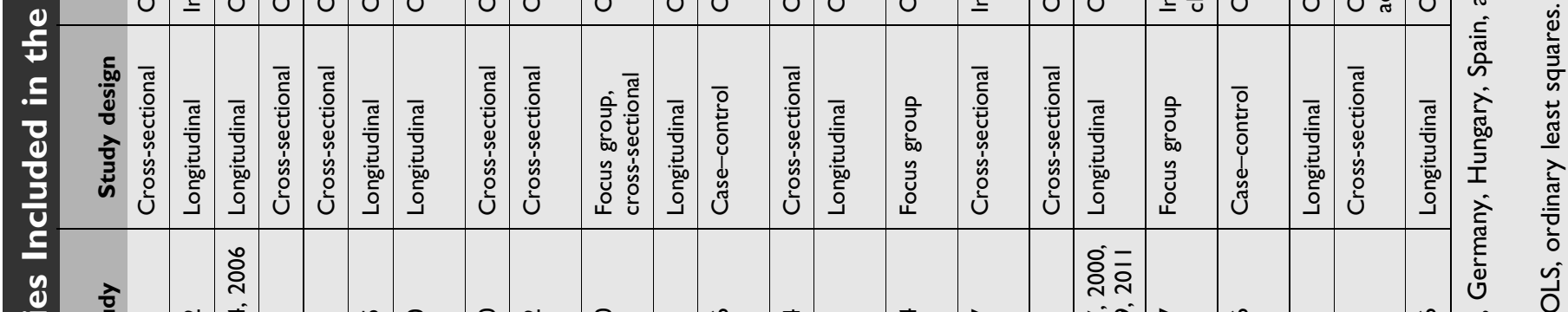

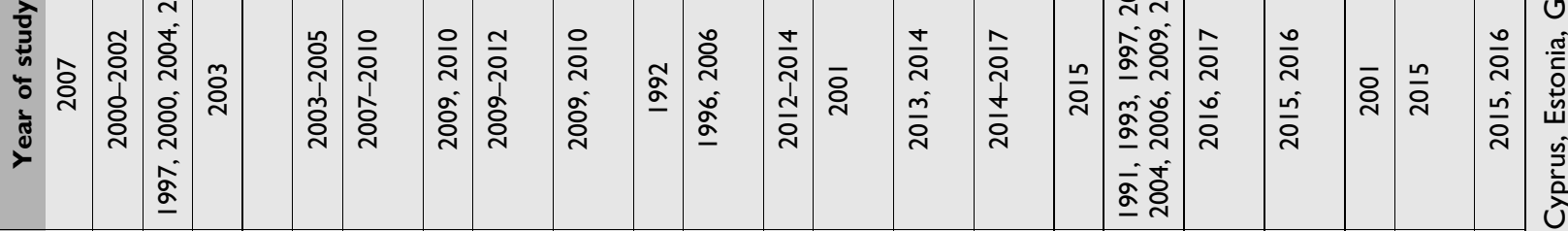

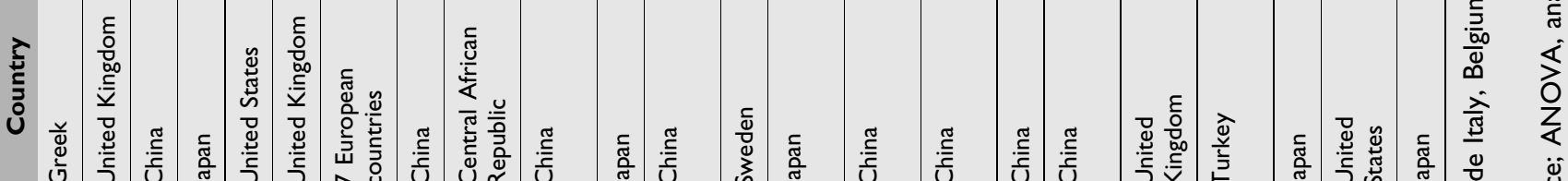

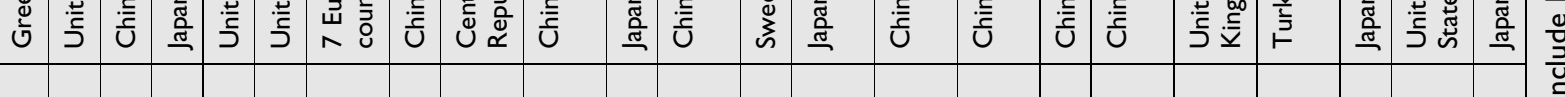

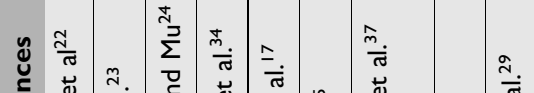

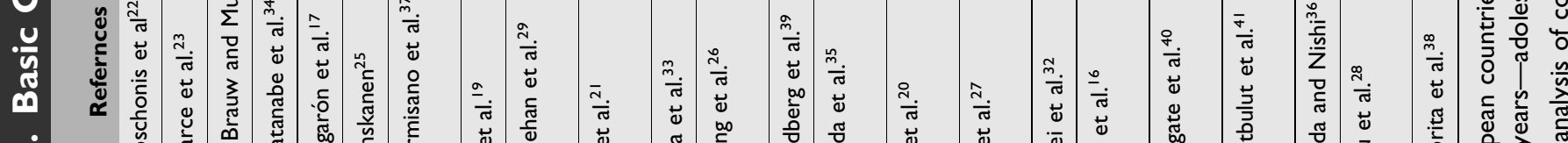

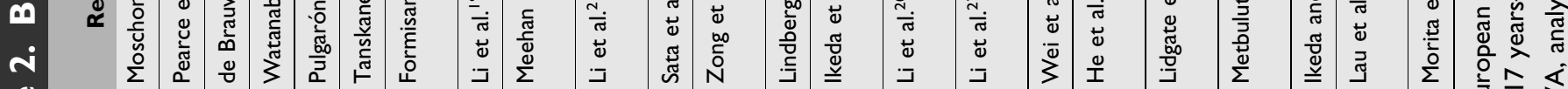
ते

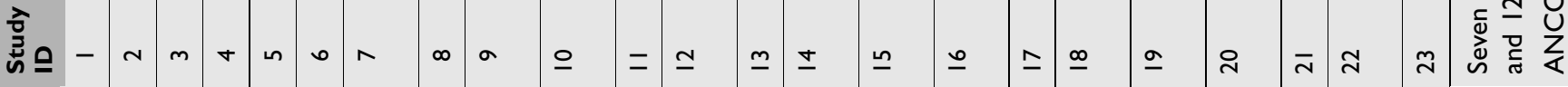




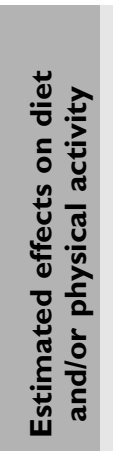

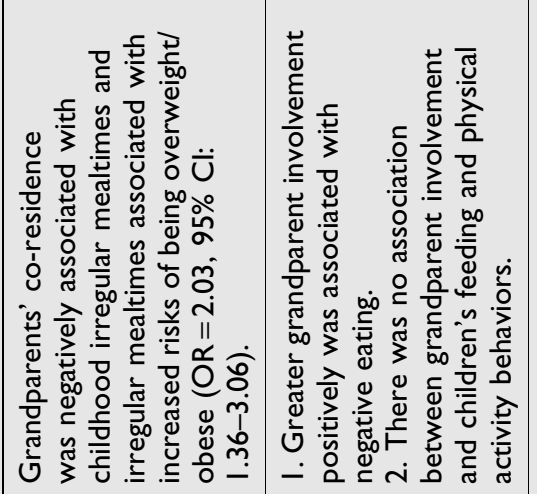

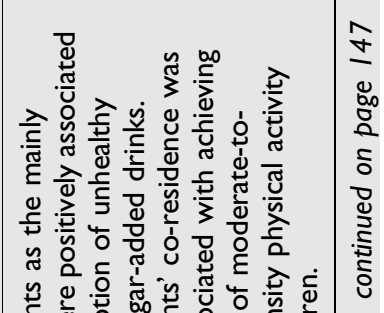

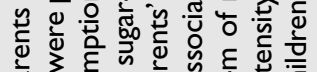

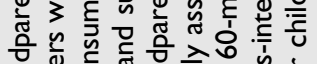

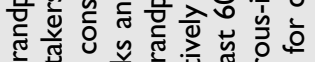

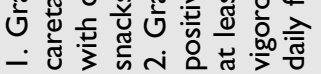

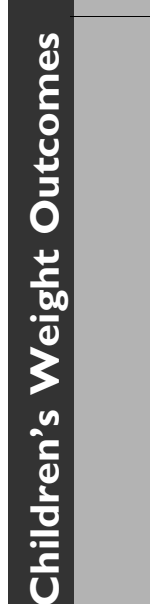

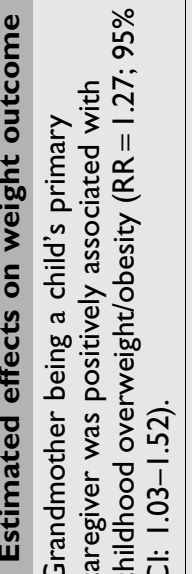

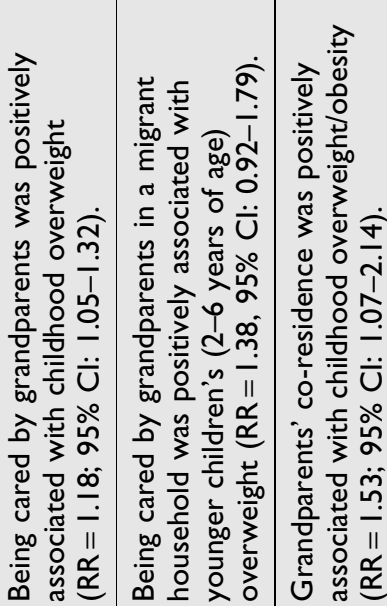

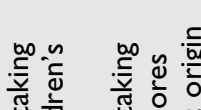

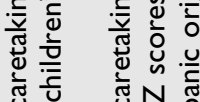

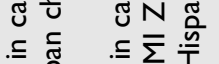

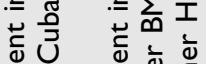

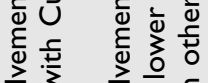

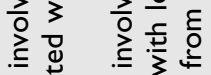

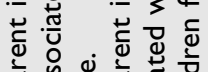

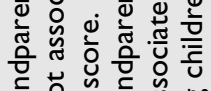

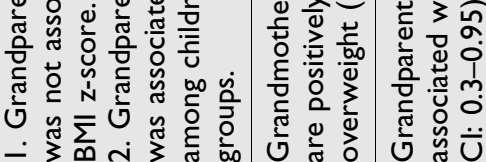

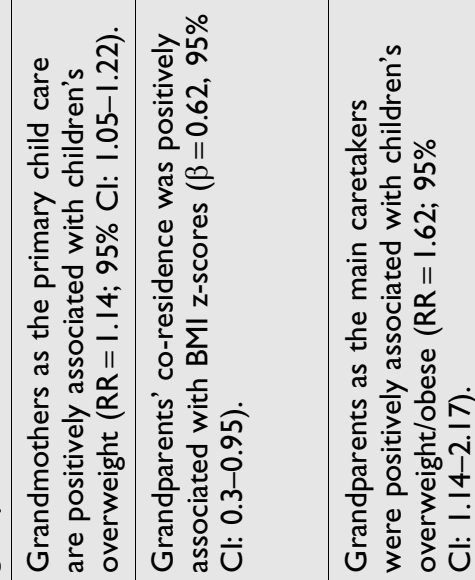

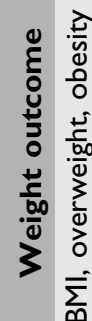

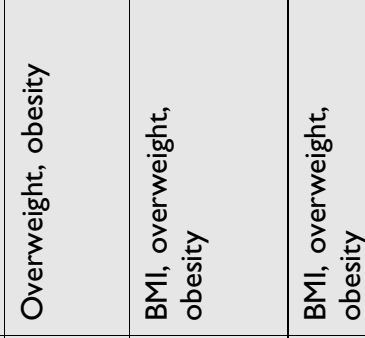

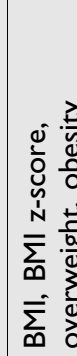

ज उ

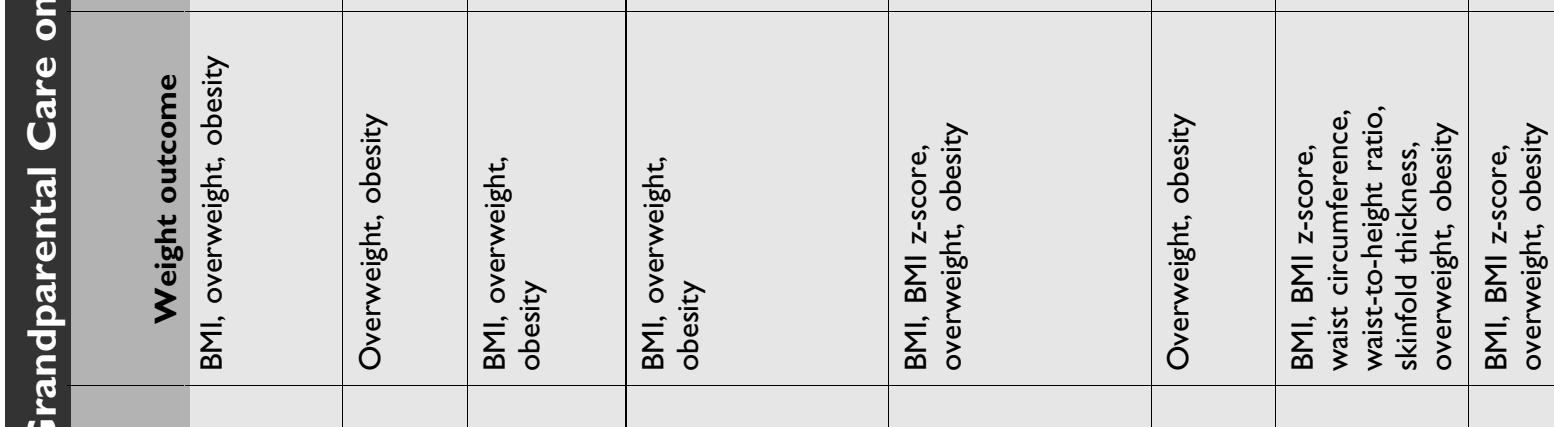

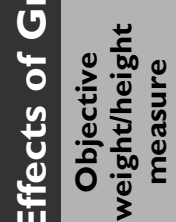

\begin{tabular}{|c|c|c|c|c|c|c|c|}
\hline$\stackrel{\Perp}{\nu}^{\Perp}$ & $\stackrel{y}{\nu}$ & $\stackrel{\Xi}{\nu}$ & $\stackrel{\varpi}{\nu}$ & 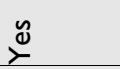 & $\stackrel{\Xi}{\rightleftharpoons}$ & $\underbrace{y}_{\nu}$ & $\stackrel{\tilde{\nu}}{\nu}$ \\
\hline 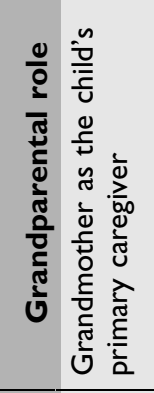 & 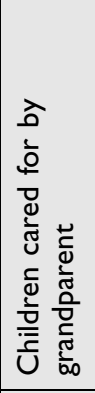 & 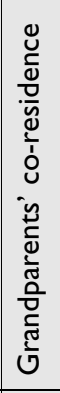 & 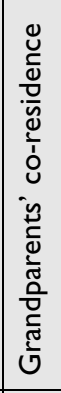 & 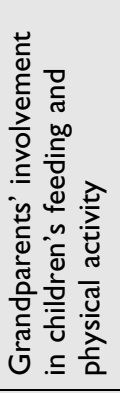 & 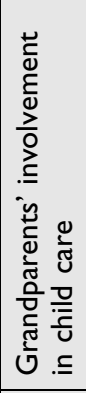 & 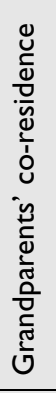 & 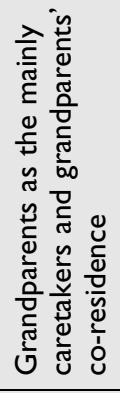 \\
\hline 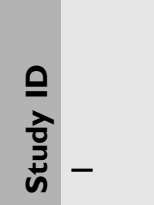 & $N$ & $m$ & $\sigma$ & in & 0 & $\lambda$ & $\infty$ \\
\hline
\end{tabular}




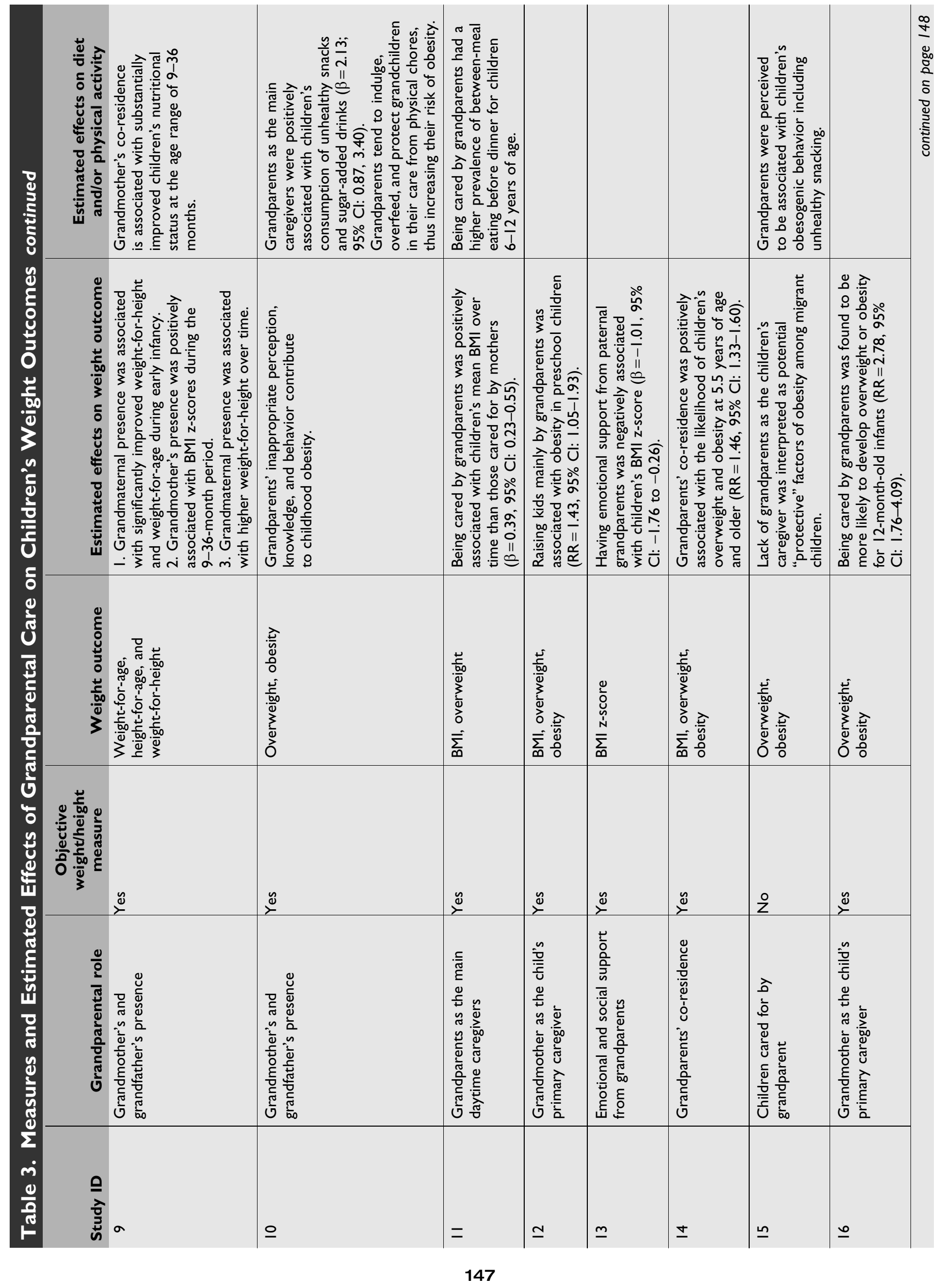




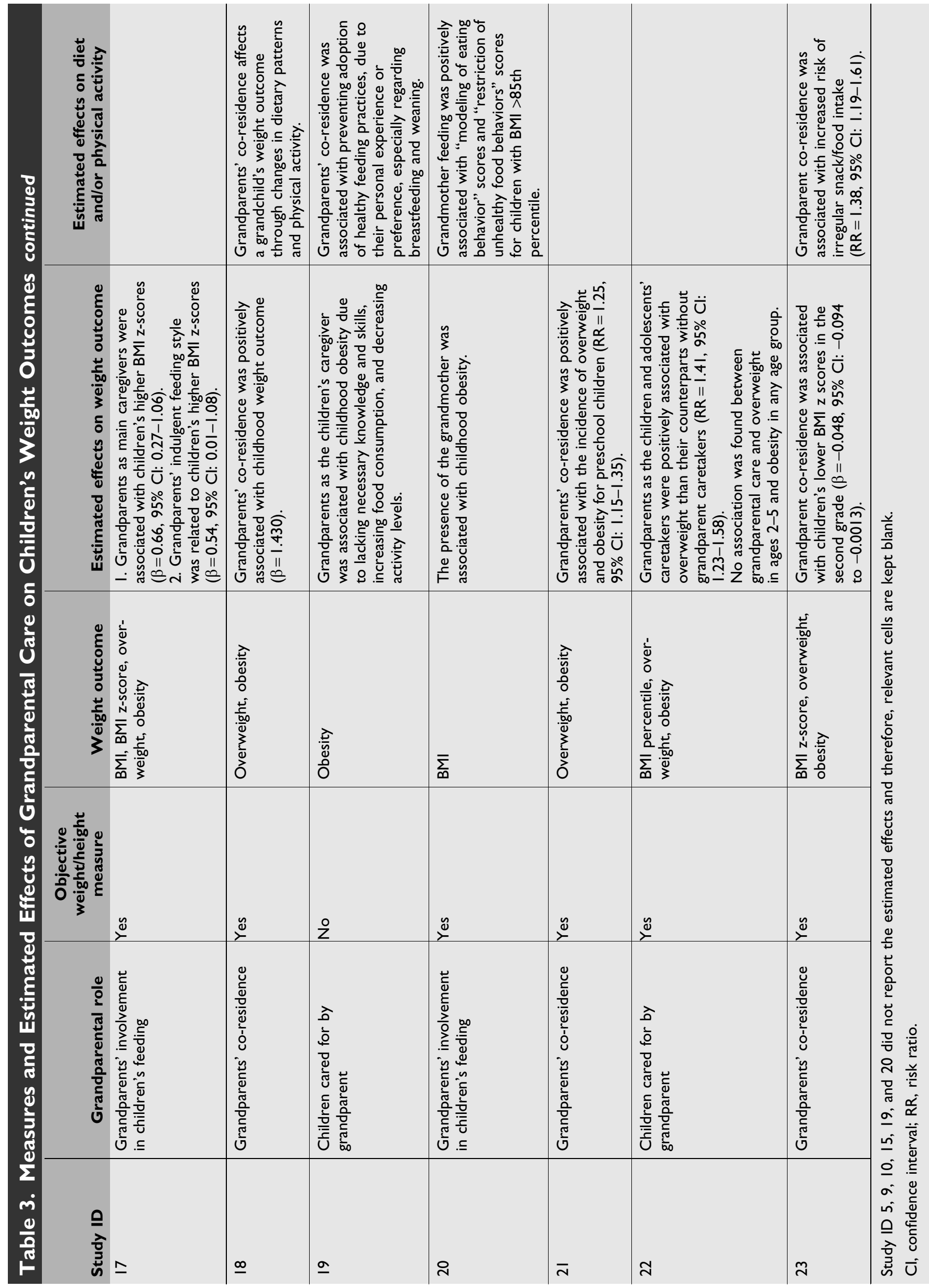


addition, grandparents' co-residence was found to be positively associated with childhood overweight and/or obesity, ${ }^{34-36}$ children's BMI z-scores, ${ }^{37}$ and children's body weight. ${ }^{16}$

However, in other studies, Lau et al. ${ }^{28}$ reported a null finding between grandparental child care and childhood overweight among young children 2-5 years of age. Pulgarón et al. ${ }^{17}$ reported that grandparent's involvement in caregiving was not associated with BMI z-scores among Cuban elementary school children 6-10 years of age. They also found that grandparents' involvement in caregiving was inversely associated with BMI z-scores among children 6-10 years of age from certain Hispanic origin groups. ${ }^{17}$ Morita et al. ${ }^{38}$ reported grandparents' co-residence to be inversely associated with BMI z-scores among children 6-7 years of age. Lindberg et al. ${ }^{39}$ reported that receiving emotional support from paternal grandparents was inversely associated with BMI z-scores among children 4-6 years of age.

The estimated effects of grandparental child care on children's diet and/or physical activity were mixed. Some studies reported mostly obesity-prompting effects of grandparental child care. Grandparents' co-residence was inversely associated with the adoption of healthy feeding practices for infants. ${ }^{36}$ Children being cared by grandparents had a higher rate of between-meal eating before dinner. ${ }^{33}$ Grandparents being a main caregiver in the family increased unhealthy snacks and sugar-sweetened beverage consumption. ${ }^{19-21}$ Grandparents' co-residence was associated with decreased physical activity among children. ${ }^{16}$

In other studies, grandparental child care was either not associated with children's diet and/or physical activity or had a positive influence in the adoption of healthy diet and physical activity behaviors. Pulgarón et al. ${ }^{17}$ found no relationship between grandparental child care and children's diet or physical activity. In another study, grandparents' co-residence was associated with better nutritional status of young children 9-36 months of age ${ }^{29}$ and reduced frequency of irregular mealtimes among children. ${ }^{34}$ Moreover, grandparents' co-residence was positively associated with the likelihood of achieving at least 60 minutes of moderate-to-vigorous-intensity physical activity per day for children. ${ }^{19}$ Children cared by grandparents were more likely to be physically active. ${ }^{33}$

\section{Meta-Analysis}

Table 4 summarizes the modeling results from the metaanalysis. Data from 14 studies were used in the metaanalysis, 10 focusing on childhood overweight/obesity and the other 4 on children's BMI z-scores. A nonsignificant Begg's test suggested lack of publication bias for the impact of grandparental child care on childhood overweight/obesity $(p=0.13)$ and children's BMI z-score $(p=0.09)$. Results from the Egger's test did not identify publication bias for the impact of grandparental child care on childhood overweight/ obesity $(p=0.07)$, but indicated the presence of publication bias for the impact of grandparental child care on children's BMI z-score ( $p=0.04)$ (Fig. 2).

Compared with children not receiving grandparental child care, children with grandparental child care had a $30 \%$ increase in childhood overweight/obesity risk $(95 \%$ confidence interval $[\mathrm{CI}]=21-40 ; I^{2}=62.5 \%$; random-effect model). In addition, grandparental child care was associated with a 0.38 point increase in children's BMI z-scores $(95 \% \mathrm{CI}=0.01$ $0.75, I^{2}$ index $=94.2 \%$; random-effect model). However, the estimated increase in children's BMI z-scores was no longer statistically significant $(\beta=0.05 ; 95 \% \mathrm{CI}=-0.28$ to 0.38 ; random-effect model) after correcting for publication bias, using the nonparametric trim-and-fill procedure. ${ }^{30}$

In meta-regression, the effect of grandparental child care on children's weight outcomes did not differ across countries (i.e., Japan, China, and United Kingdom, vs. others, $p=0.08,0.11$, and 0.12 , respectively) or by grandparents' roles (i.e., grandparents as the main caregiver vs. coresidence, $p=0.43$ ).

Table 4. Results from Meta-Analysis and Publication Bias Tests

\begin{tabular}{|c|c|c|c|c|c|c|c|c|}
\hline \multirow[b]{2}{*}{ Outcome } & \multirow[b]{2}{*}{ Study ID } & \multirow[b]{2}{*}{$\begin{array}{l}\text { Studies included } \\
\text { in meta-analysis }\end{array}$} & \multirow[b]{2}{*}{ 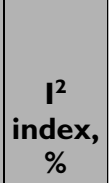 } & \multirow{2}{*}{$\begin{array}{l}\text { Pooled estimate } \\
\text { (coefficient for BMI } \\
\text { z-score and RR } \\
\text { of childhood } \\
\text { overweight/obesity) }\end{array}$} & \multirow{2}{*}{$\begin{array}{l}\text { Trim-and-fill } \\
\text { estimate (coefficient } \\
\text { for BMI z-score } \\
\text { and RR of childhood } \\
\text { overweight/obesity) }\end{array}$} & \multirow[b]{2}{*}{ Model } & \multicolumn{2}{|c|}{$\begin{array}{l}\text { Publication } \\
\text { bias test }\end{array}$} \\
\hline & & & & & & & $\begin{array}{c}\text { Egger's } \\
\text { test }\end{array}$ & $\begin{array}{c}\text { Begg's } \\
\text { test }\end{array}$ \\
\hline BMI z-score & $7,11,17,23$ & $\begin{array}{l}\text { Formisano et al. }{ }^{37} \text {; } \\
\text { Sata et al. }{ }^{33} ; \text { Wei } \\
\text { et al. }{ }^{32} ; \text { Morita et al. }{ }^{38}\end{array}$ & 94.2 & $\begin{array}{c}\text { Coefficient: } 0.38 \\
(0.01-0.75)\end{array}$ & $\begin{array}{l}\text { Coefficient: } 0.05 \\
(-0.28 \text { to } 0.38)\end{array}$ & RE & $p=0.04$ & $p=0.09$ \\
\hline $\begin{array}{l}\text { Childhood } \\
\text { overweight/ } \\
\text { obesity }\end{array}$ & $\begin{array}{l}1,2,3,4,6,8 \\
12,14,21,22\end{array}$ & $\begin{array}{l}\text { Moschonis et al. }{ }^{22} \text {; } \\
\text { Pearce et al. }{ }^{23} ; \text { de } \\
\text { Brauw and } \mathrm{Mu}^{24} ; \\
\text { Watanabe et al. }{ }^{34} ; \text { Li } \\
\text { et al. }{ }^{19} \text {; Tanskanen }{ }^{25} \text {; } \\
\text { Zong et al. }^{26} \text {; Ikeda } \\
\text { et al. }{ }^{35} \text {; Ikeda and } \\
\text { Nishi }^{36} \text {; Lau et al. }{ }^{28}\end{array}$ & 62.5 & RR: I.30 (I.2I-I.40) & RR: I.20 (I.I0-I.3I) & RE & $p=0.07$ & $p=0.13$ \\
\hline
\end{tabular}

RE, random-effect model. 

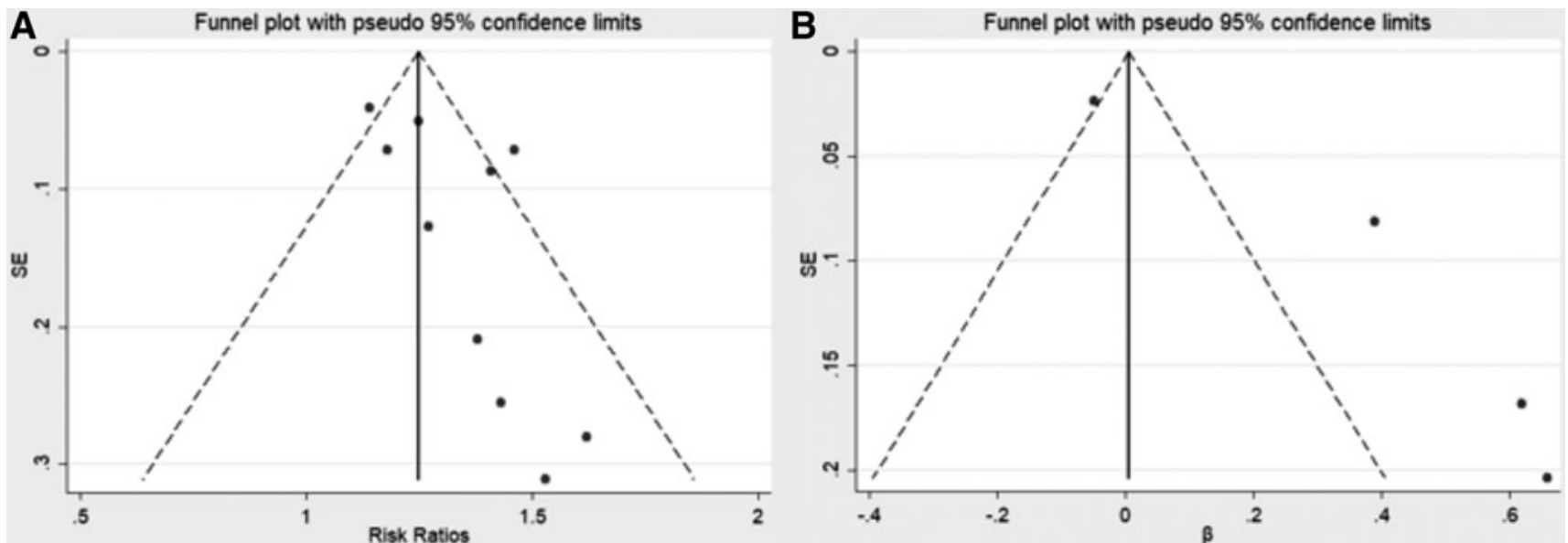

Figure 2. Funnel plots. (A) Funnel plot of grandparental care and childhood overweight. (B) Funnel plot of grandparental care and childhood BMI z-score.

\section{Study Quality Assessment}

Table 5 reports criterion-specific and global ratings from the study quality assessment. The included studies on average scored 8 out of 14 , with a range from 5 to 11 . All studies included in the review clearly stated the research question and objective, specified and defined the study population, had a participation rate above $50 \%$, recruited participants from the same or similar populations during the same time period, and prespecified and uniformly applied inclusion and exclusion criteria to all potential participants. Most studies measured and statistically adjusted key potential confounding variables for their impact on the relationship between exposures and outcomes $(n=16)$, had an attrition rate less than $20 \%(n=18)$, and implemented valid and reliable outcome measures $(n=21)$.

Nine studies had a reasonably long follow-up period that was sufficient for changes in outcomes to be observed. Seven studies assessed the exposures more than once during the study period. In contrast, none of the studies measured exposures of interest (e.g., grandparents being a main caregiver in the family or grandparents' co-residence) before the outcomes, or had the outcome assessors blinded to the exposure status of the participants. Only two studies examined the different levels of exposure in relationship to the outcome, and only one study provided a sample size justification using power analysis.

\section{Discussion}

This study systematically reviewed the literature on the relationship between grandparental child care and childhood obesity. A total of 23 studies were identified from the keyword and reference search of 4 bibliographic databases. Meta-analysis found that grandparental child care was associated with an $\sim 30 \%$ increase in childhood overweight/obesity risk. However, grandparental child care was not associated with children's BMI z-scores after correcting for publication bias. In addition, findings on the relationship between grandparental child care and children's dietary and physical activity behaviors are mixed, with null, positive, and negative findings reported.

Qualitative studies across western and eastern cultures shed light on why there is an increased obesity risk with grandparental child care. Grandparents can influence children's body weight through mechanisms of perception and feeding practices. ${ }^{21,42,43}$ Some grandparents perceived heavier body weight in children as an indicator of good nutrition. ${ }^{42}$ As such, children were urged to eat larger meals and more frequent meals. ${ }^{21,44}$ Some grandparents were more likely to provide children with unhealthy food (e.g., sweets and fried food) as an expression of love and kindness. ${ }^{19,21}$ In some cultures, grandparents may be more likely to excuse children from doing household chores, an important form of physical activity. ${ }^{21}$

Although meta-analysis identified a positive association between grandparental child care and childhood overweight/ obesity, grandparental child care was not associated with children's BMI z-scores. This is likely due to lack of statistical power given that only four studies included in this review analyzed children's BMI z-scores. It is also possible that the relationship between grandparental child care and childhood obesity is more complicated than a simple linear relationship. In addition, variation in study designs and measurements may have contributed to the seemingly inconsistent findings.

Furthermore, studies that evaluated the behavioral pathways linking grandparental child care to adiposity in children produced conflicting findings with positive, negative, and null findings. Substantial heterogeneities in study design and populations among the included studies may have contributed to the mixed findings.

We included a variety of study designs for a more inclusive review. Study populations covered a wide range of age groups from infants to adolescents from nine countries with diverging cultural beliefs, family practices, and economic development. Significant cross-cultural differences in parenting style, interpersonal dynamics, role satisfaction, 


\section{Table 5. Study Quality Assessment}

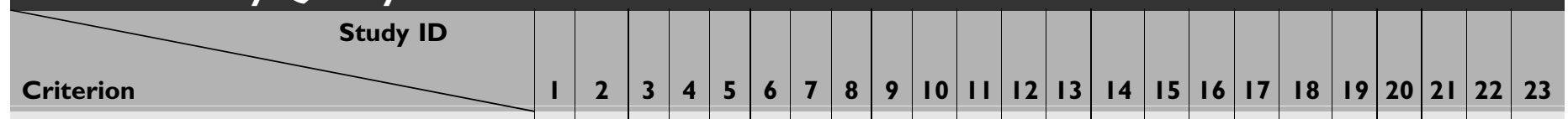

I. Was the research question or objective in this article clearly stated?

2. Was the study population clearly specified and defined?

3. Was the participation rate of eligible persons at least $50 \%$ ?

4. Were all the subjects selected or recruited from the same or similar populations (including the same time period)? Were inclusion and exclusion criteria for being in the study prespecified and applied uniformly to all participants?

5. Was a sample size justification, power description, or variance and effect estimates provided?

6. For the analyses in this article, were the exposure(s) of interest measured before the outcome(s) being measured?

7. Was the timeframe sufficient so that one could reasonably expect to see an association between exposure and outcome if it existed?

8. For exposures that can vary in amount or level, did the study examine different levels of the exposure as related to the outcome (e.g., categories of exposure, or exposure measured as continuous variable)?

9. Were the exposure measures (independent variables) clearly defined, valid, reliable, and implemented consistently across all study participants?

10. Was the exposure(s) assessed more than once over time?

II. Were the outcome measures (dependent variables) clearly defined, valid, reliable, and implemented consistently across all study participants?

12. Were the outcome assessors blinded to the exposure status of participants?

13. Was loss to follow-up after baseline $20 \%$ or less?

14. Were key potential confounding variables measured and adjusted statistically for their impact on the relationship between exposure(s) and outcome(s)?

Total score
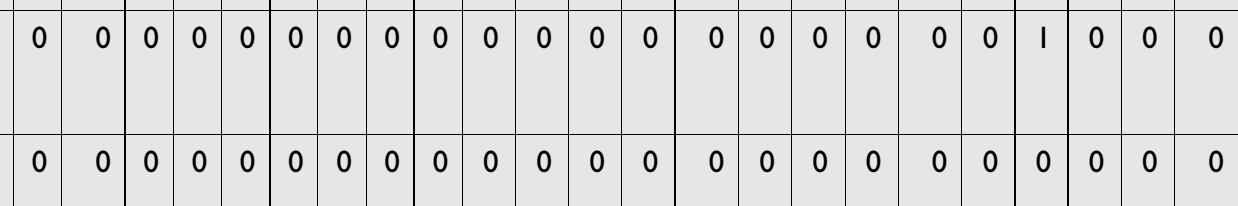

\begin{tabular}{|c|c|c|c|c|c|c|c|c|c|c|c|c|c|c|c|c|c|c|c|c|c|c|}
\hline 0 & I & I & 0 & 0 & 0 & I & 0 & I & 0 & $\mathrm{I}$ & 0 & 0 & I & 0 & 0 & 0 & $\mathrm{I}$ & 0 & 0 & I & 0 & I \\
\hline
\end{tabular}

$\begin{array}{llllllllllllllllllllllllll}0 & 1 & 0 & 0 & 0 & 0 & 0 & 0 & 0 & 0 & 0 & 0 & 1 & 0 & 0 & 0 & 0 & 0 & 0 & 0 & 0 & 0 & 0\end{array}$
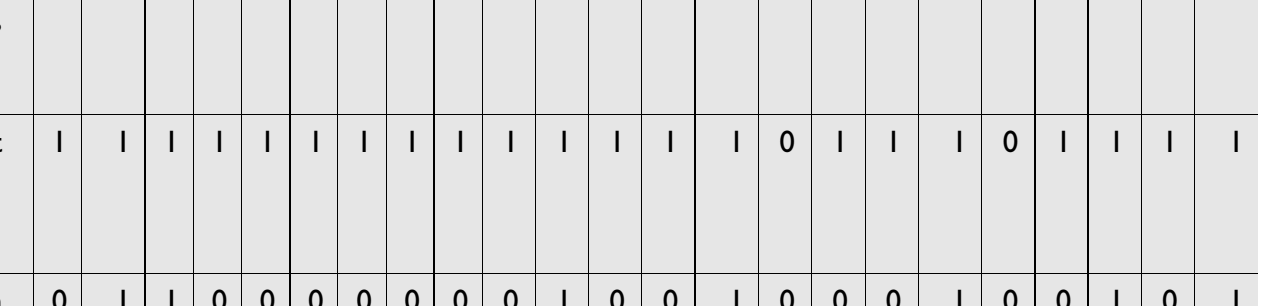

(1)

\begin{tabular}{|l|l|l|l|l|l|l|l|l|l|l|l|l|l|l|l|l|l|l|l|l|l}
\hline I & I & I & I & I & I & I & I & I & I & I & I & I & I & 0 & I & I & I & 0 & I & I & I \\
\hline
\end{tabular}

$\begin{array}{llllllllllllllllllllllllllll}0 & 0 & 0 & 0 & 0 & 0 & 0 & 0 & 0 & 0 & 0 & 0 & 0 & 0 & 0 & 0 & 0 & 0 & 0 & 0 & 0 & 0 & 0\end{array}$

\begin{tabular}{|c|c|c|c|c|c|c|c|c|c|c|c|c|c|c|c|c|c|c|c|c|c|c|}
\hline I & I & 0 & 1 & 1 & I & 0 & I & 1 & 1 & 0 & 1 & 0 & I & 1 & I & 1 & 1 & 1 & I & 0 & 1 & I \\
\hline 1 & 1 & 0 & I & 0 & 1 & 1 & 1 & 0 & 1 & 1 & I & I & 1 & 0 & 0 & 1 & 1 & 0 & 0 & 1 & 1 & I \\
\hline 8 & 11 & 8 & 8 & 7 & 8 & 8 & 8 & 8 & 8 & 9 & 8 & 8 & 10 & 5 & 7 & 8 & 10 & 5 & 8 & 9 & 8 & 10 \\
\hline
\end{tabular}

This study quality assessment tool was adopted from the National Institutes of Health's Quality Assessment Tool for Observational Cohort and Cross-Sectional Studies. For each criterion, a score of I was assigned if yes was the response, whereas a score of 0 was assigned otherwise. A study-specific global score, ranging from 0 to 14 , was calculated by summing up scores across all 14 criteria. Study quality assessment helped measure strength of scientific evidence, but was not used to determine the inclusion of studies. 
and attachment to the grandchild among grandparents providing child care have been reported. ${ }^{45}$ Although countryspecific differences regarding the relationship of grandparental child care and childhood obesity were not evident in meta-regression, it is possible that our analysis was underpowered to detect such differences.

Based on this systematic review, we identified a few major limitations of this review study and areas for future research.

First, all studies adopted an observational design, which is prone to self-selection and confounding bias. Familybased obesity interventions that incorporate grandparents are warranted to assess the causal impact of grandparental child care on children's weight outcomes.

Second, currently, studies tend to be scattered across countries and child age groups, and a "critical mass" of evidence is yet to form. A sizable cluster of studies focusing on age-specific groups within a country and/or cross-cultural comparisons is needed to uncover the more nuanced relationship between grandparental practices and child weight outcomes.

Third, the degree of grandparents' involvement in grandchildren's care and the specific duties they play are not specifically defined, measured, or described in most studies. It is perceivable that a grandparent who plans and cooks for family meals most of the time likely exerts more control over a child's diet behaviors than a grandparent whose primary responsibilities are to pick up the child from school. Better definition and measurement of grandparental child care roles and duties will further our understanding of the role that grandparents play in shaping children's behaviors and weight outcomes.

Moreover, the complex family dynamic and interactions between grandparents and parents in child care and how these interactions affect childhood obesity are understudied. Systematic and field-validated measures should be implemented to comprehensively document the multifaceted grandparental child care activities in relationship to children's health. The behavioral pathways linking grandparental child care to children's weight outcomes should be elucidated, which is expected to provide valuable information for the design of family-orientated childhood obesity interventions. The connection of other behaviors that influence energy balance, such as sleep and social media usage, to grandparental child care should also be examined.

The substantial heterogeneity in diet and physical activity measures prevented meta-analysis, so that we summarized corresponding findings narratively. Publication bias tends to exist on the relationship between grandpaternal care and children's BMI z-scores, which call for more studies and studies reporting null or negative findings.

In conclusion, this study systematically reviewed the scientific literature on the relationship between grandparental child care and childhood obesity. Meta-analysis found that grandparental child care was associated with a $30 \%$ increase in childhood overweight/obesity risk. However, we also found a lack of linear association between grandparental child care and children's BMI z-scores and mixed findings regarding the impact of grandparental child care on children's dietary and physical activity behaviors. Therefore, it is hard to draw a firm conclusion regarding the influence of grandparental child care on childhood obesity. Future research should focus on a specific child age group within a country, adopt systematic and fieldvalidated measures on grandparental child care, and elucidate the pathways linking grandparental child care to children's weight outcomes.

\section{Author Disclosure Statement}

No competing financial interests exist.

\section{References}

1. An R. Health care expenses in relation to obesity and smoking among US adults by gender, race/ethnicity, and age group: 19982011. Public Health 2015;129:29-36.

2. Obesity and its relation to mortality and morbidity costs. Available at https://www.soa.org/Files/Research/Projects/research-2011-obesityrelation-mortality.pdf Last accessed August 18, 2019.

3. Finkelstein EA, Trogdon JG, Cohen JW, Dietz W. Annual medical spending attributable to obesity: Payer- and service-specific estimates. Health Aff (Millwood) 2009;28:w822-w831.

4. Danaei G, Ding EL, Mozaffarian D, et al. The preventable causes of death in the United States: Comparative risk assessment of dietary, lifestyle, and metabolic risk factors. PLoS Med 2009;6: e1000058.

5. An R. Racial/ethnic disparity in obesity among US youth, 19992013. Int J Adolesc Med Health 2015;29:pii:/j/ijamh.2017.29.issue4/ijamh-2015-0068/ijamh-2015-0068.xml.

6. Childhood Obesity Facts. Available at https://www.cdc.gov/ healthyschools/obesity/facts.htm Last accessed August 18, 2019.

7. de Onis M, Blössner M, Borghi E. Global prevalence and trends of overweight and obesity among preschool children. Am J Clin Nutr 2010;92:1257-1264.

8. Wang Y, Lim H. The global childhood obesity epidemic and the association between socio-economic status and childhood obesity. Int Rev Psychiatry 2012;24:176-188.

9. Daniels SR, Arnett DK, Eckel RH, et al. Overweight in children and adolescents: Pathophysiology, consequences, prevention, and treatment. Circulation 2005; 111:1999-2012.

10. Nepper MJ, Chai W. Associations of the home food environment with eating behaviors and weight status among children and adolescents. J Nutr Food Sci 2015;S12:004.

11. Loprinzi PD, Trost SG. Parental influences on physical activity behavior in preschool children. Prev Med 2010;50:129-133.

12. Ash T, Agaronov A, Young TL, et al. Family-based childhood obesity prevention interventions: A systematic review and quantitative content analysis. Int J Behav Nutr Phys Act 2017;14:113.

13. Davis MM, McGonagle K, Schoeni RF, Stafford F. Grandparental and parental obesity influences on childhood overweight: Implications for primary care practice. J Am Board Fam Med 2008;21:549-554.

14. Share M, Kerrins L. The role of grandparents in childcare in Ireland: Towards a research agenda. Irish J Appl Soc Stud 2009;9:8.

15. Who's Minding the Kids? Child Care Arrangements: Spring 2011. Available at https://www.census.gov/prod/2013pubs/p70-135.pdf Last accessed August 20, 2019. 
16. He Q, Li X, Wang R. Childhood obesity in China: Does grandparents' coresidence matter? Econ Hum Biol 2018; 29:56-63.

17. Pulgarón ER, Patiño-Fernández AM, Sanchez J, et al. Hispanic children and the obesity epidemic: Exploring the role of abuelas. Fam Syst Health 2013;31: 274-279.

18. Grandparents as caregivers. Available at https://www.questia.com/ $\mathrm{read} / 127495767 /$ handbook-on-grandparenthood Last accessed $\mathrm{Au}-$ gust 20, 2019.

19. Li B, Adab P, Cheng K. Family and neighborhood correlates of overweight and obesogenic behaviors among Chinese children. Int J Behav Med 2014;21:700-709.

20. Li B, Lin R, Liu W, et al. Differences in perceived causes of childhood obesity between migrant and local communities in China: A qualitative study. PLoS One 2017;12:e0177505.

21. Li B, Adab P, Cheng KK. The role of grandparents in childhood obesity in China-evidence from a mixed methods study. Int $J$ Behav Nutr Phys Act 2015;12:91.

22. Moschonis G, Tanagra S, Vandorou A, et al. Social, economic and demographic correlates of overweight and obesity in primaryschool children: Preliminary data from the Healthy Growth Study. Public Health Nutr 2010;13(10A):1693-1700.

23. Pearce A, Li L, Abbas J, et al. Is childcare associated with the risk of overweight and obesity in the early years? Findings from the UK Millennium Cohort Study. Int J Obes (Lond) 2010;34:1160-1168.

24. de Brauw A, Mu R. Migration and the overweight and underweight status of children in rural China. Food Policy 2011;36:88-100.

25. Tanskanen AO. The association between grandmaternal investment and early years overweight in the UK. Evol Psychol 2013;11: $417-425$.

26. Zong XN, Li H, Zhang YQ. Family-related risk factors of obesity among preschool children: Results from a series of national epidemiological surveys in China. BMC Public Health 2015;15:927.

27. Li Q, Liang F, Liang $W$, et al. The influence of different caregivers on infant growth and development in China. Front Pediatr.2017;5:243.

28. Lau JD, Au LY, Chao E, et al. The association of grandparent care with childhood overweight and obesity in Chinese American families. Child Obes 2019;15:14-20.

29. Meehan CL, Helfrecht C, Quinlan RJ. Cooperative breeding and Aka children's nutritional status: Is flexibility key? Am J Phys Anthropol 2014; 153:513-525.

30. Contour-enhanced funnel plots for meta-analysis. Available at https://journals.sagepub.com/doi/pdf/10.1177/1536867X0800800206 Last accessed August 20, 2019.

31. Quality assessment tool for observational cohort and cross-sectional studies. Available at https://www.nhlbi.nih.gov/health-topics/studyquality-assessment-tools Last accessed August 28, 2019.

32. Wei X, Ma Y, Hu J, et al. Predicting weight status in Chinese preschool children: Independent and interactive effects of caregiver types and feeding styles. Public Health Nutr 2017;21:1123-1130.

33. Sata M, Yamagishi K, Sairenchi T, et al. Impact of caregiver type for 3-year-old children on subsequent between-meal eating habits and being overweight from childhood to adulthood: A 20-year follow-up of the Ibaraki Children's Cohort (IBACHIL) study. $J$ Epidemiol 2015;25:600-607.
34. Watanabe E, Lee JS, Kawakubo K. Associations of maternal employment and three-generation families with pre-school children's overweight and obesity in Japan. Int J Obes (Lond) 2011;35:945952.

35. Ikeda N, Fuse K, Nishi N. Changes in the effects of living with no siblings or living with grandparents on overweight and obesity in children: Results from a national cohort study in Japan. PLoS One 2017;12:e0175726.

36. Ikeda N, Nishi N. First incidence and associated factors of overweight and obesity from preschool to primary school: Longitudinal analysis of a national cohort in Japan. Int J Obes (Lond) 2019;43: 751-760.

37. Formisano A, Hunsberger M, Bammann K, et al. Family structure and childhood obesity: Results of the IDEFICS Project. Public Health Nutr 2014;17:2307-2315.

38. Morita A, Ochi M, Isumi A, Fujiwara T. Association between grandparent coresidence and weight change among first-grade Japanese children. Pediatr Obes2019;29:12524.

39. Lindberg L, Ek A, Nyman J, et al. Low grandparental social support combined with low parental socioeconomic status is closely associated with obesity in preschool-aged children: A pilot study. Pediatr Obes2016;11:313-316.

40. Lidgate ED, Li B, Lindenmeyer A. A qualitative insight into informal childcare and childhood obesity in children aged $0-5$ years in the UK. BMC Public Health 2018;18:1229.

41. Metbulut AP, Ozmert EN, Teksam O, Yurdakok K. A comparison between the feeding practices of parents and grandparents. Eur $J$ Pediatr.2018;177:1785-1794.

42. Jiang J, Rosenqvist $\mathrm{U}$, Wang $\mathrm{H}$, et al. Influence of grandparents on eating behaviors of young children in Chinese three-generation families. Appetite 2007;48:377-383.

43. Roberts M, Pettigrew S. The influence of grandparents on children's diets. J Res Consum 2010;18:1-8.

44. Dong F, Howard AG, Herring AH, et al. Parent-child associations for changes in diet, screen time, and physical activity across two decades in modernizing China: China Health and Nutrition Survey 1991-2009. Int J Behav Nutr Phys Act 2016;13:118

45. Wang CD, Hayslip B Jr, Sun Q, Zhu W. Grandparents as the primary care providers for their grandchildren: A cross-cultural comparison of Chinese and U.S. samples. Int J Aging Hum Dev 2019. [Epub ahead of print]; DOI: 10.1177/0091415018824722.

Address correspondence to: Jing Shen, $P h D$

Overseas Chinese College Capital University of Economics and Business 121 Zhangjialukou, Huaxiang Fengtai District Beijing 100070

China

E-mail: shenjing945@yahoo.com 